\title{
Thoughts on the Future of Data Analytics Education in College Fashion Curricula
}

\author{
Dr. Les Sztandera* \\ School of Business, Thomas Jefferson University, USA
}

*Corresponding author: Dr. Les Sztandera, School of Business, Thomas Jefferson

University, USA.

Received Date: June 08, 2020

Published Date: June 24, 2020

\begin{abstract}
The fashion industry is being transformed, as once valuable brands find themselves being increasingly commoditized. As the middle price point brands change their differentiating strategies, the effect percolates to the top designers as well, forcing everyone in the industry to carefully examine the evolving nature of advantage in the market. This response is certainly going to be influenced by college graduates entering the industry. Thus, education for students preparing to enter fashion industry will need to entertain a vast array of data analytics technologies.
\end{abstract}

Keywords: Data analytics; College fashion curricula

Abbreviations: TJU: Thomas Jefferson University; FMM: Fashion Merchandizing and Management: MBA - Master of Business Administration

\section{Introduction}

It has been almost eightyears already since the Harvard Business Review declared Business Analytics the one and only future top job of the 21st century [1], and the glamour of that job has indeed not shown any signs of waning since that announcement. The days of easily disrupting fashion businesses and markets with iterations of existing technology are definitely over. Creating "value" through planned practices and services that no longer will be wanted in the future (as the future has already started), even though they may still be in good working order, as well as optimized supply chains are no longer interesting or even acceptable to fashion industry with high expectations of success measures, functionality, and differentiation. Thus, education for students preparing to enter fashion industry will need to entertain a vast array of data analytics technologies.

This paper presents the need for dynamic case model college courses that can present real-world problem-solving concepts that are not only technical but also business-related. As a means of assuring that curricula meet industry real-world situations the paper proposes that the future will allow analytics-based knowledge management system for evaluations by practitioners.

\section{Discussion}

Thomas Jefferson University (TJU) Fashion Merchandizing and Management (FMM) students in the School of Business are moving beyond the current commercial and financial understanding of innovation as they go through an educational experience that requires break through ideas, approaching industry challenges with an experimental mind frame, as well as compelling insights and a focus on the human element with data written all over it.

Thomas Jefferson University (TJU) new Data Analytics BusinessCore curriculum [2], launching during Fall 2020 semester, consists of four undergraduate courses at the School of Business, and is a required course of study for all Fashion Merchandising and Management (FMM) students. The courses: Introduction to 
Business Analytics, Statistical Data Analytics, Data Mining and Predictive Analytics, Operations and Data Analytics, also form a Business Analytics Minor that could be taken by any Thomas Jefferson University student. At the graduate level, Thomas Jefferson University offers an innovation MBA degree with a concentration in Business Analytics.

Fashion retailers are increasingly turning to Data Analytics to keep up with the latest trends and client demands. The fashion industry is just beginning to use Data Analytics to solve their problems, and it has been fascinating to see how it has been utilizing its potential thus far [3]. Thomas Jefferson University graduates will surely be staying on top of that and providing innovation there.

Business Analytics is a powerful and essential capability for fashion firms to be competitive. The quantity, quality, and diversity of available data continue to grow, creating new and significant opportunities for businesses to use data to improve their decisions with respect to both internal resources, as well as external relationships with suppliers and customers. Making effective use of the abundance of data, to which firms have access, allows for better predictions, better decisions, and the formation of better differentiating strategies. Business analytics provides the means to make actionable, impactful, and forward looking decisions from the large amounts of data [4]. The Data Analytics Business Core curriculum will provide students with the cutting-edge knowledge and skills to identify, understands, and deliver insights from large datasets and enable internal and external clients with organizational success and competitive advantages.

This curriculum also serves as Applied Business AnalyticsMinor for any undergraduate degree student at the University. It provides students with the skills needed to implement and oversee datadriven decisions, including (i) collecting, managing and describing datasets, (ii) making inferences and predictions from data, and (iii) preparing optimal and robust decisions. Business analytics makes extensive use of statistical analysis and the application of business analytics spanning all functional areas. The business analytics toolbox will be of value for students in all majors seeking to make data driven recommendations and decisions. Knowledge acquired can use for trend analysis, customer behaviour analysis, and forecasting [5]. As fashion industry generates all five types of data: numbers, text, images, audio, and video and it is the era of fast fashion, the data are rapidly growing and evolving.Hence, these data have been termed as fashion big data.

Following is a broad classification of the fashion data based on [6]: materials/fabrics, body scan data, consumer colour preferences, production pattern making, and design concepts.

The engineered materials/fabrics are desired for textile/ fashion industry applications [7,8]. Such materials/fabrics, exhibiting consumer preferences as well as tactile comfort, can be computationally designed. Through the use of an extensive database that contains hand feel, mechanical, construction, and tactile comfort data for fabrics, desired comfort can be predicted by measuring a limited number of properties [9]. Output systems can be optimized to exhibit the highest level of comfort by engineering a material/fabric with specific properties. Using an extensive fabric database, the most significant hand feel, mechanical, and construction properties influencing tactile fabric comfort, were identified [9]. This was done through the use of data processing analysis of hand feel, mechanical, construction fabric properties, and perceived tactile comfort, using B un-standardized coefficients and Beta standardized Coefficients, among other data analytics techniques. Body scan data can be either 2D (conventional body measurement) or 3D (collected through body scanners). Consumer colour preferences are important aspects that influence human mood, and behaviour, in general. Kobayashi's color image scale [6] indicates three attributes: warm /cool, soft/hard, and clear/gray, which associate with hue, chroma, and value. These attributes have been shown with human emotions. Production pattern making plays an important role in product functionality and durability. Finally design concepts are influenced by human mood and emotions, as well as fashion trends.

\section{Conclusion}

As fashion retailers are increasingly turning to Data Analytics to keep up with the latest trends and client demands, education for students preparing to enter fashion industry will need to entertain a vast array of data analytics technologies. As a means of assuring that curricula meet industry real-world situations, the fashion industry needs to embrace and incorporate analytics-based knowledge management system to be used by practitioners.

\section{Acknowledgement}

None.

\section{Conflict of Interest}

None.

\section{References}

1. Davenport TH, Patil DJ (2012) Data Scientist: The Sexiest Job of the $21^{\text {st }}$ Century, Harvard Business Review.

2. Datta A, Naidu J, Opella J, Russel P, Sztandera L (2019) School of Business Applied Business Analytics Working Group Report. Thomas Jefferson University: 1-74.

3. Silva E, Hassani H, Madsen D (2019) Big Data in Fashion: Transforming the Retail Sector. Journal of Business Strategy 41(4): 21-27.

4. Sztandera L (2014) Computational Intelligence in Business Analytics: Concepts, Methods, and Tools for Big Data Applications, Pearson Publishing, USA

5. Frank C, Garg A, Raheja A, Sztandera LM (2003) Forecasting Women's Apparel Sales Using Mathematical Modeling International Journal of Clothing Science and Technology 15(2): 107-125

6. Jain S, Bruniaux J, Zeng X, Bruniaux P (2017) Big Data in Fashion Industry. IOP Conference Series: Materials Science and Engineering 254, 152005.

7. Karthikeyan B and Sztandera LM (2010) Analysis of Tactile Perceptions of Textile Materials using Artificial Intelligence Techniques - Part -1: Forward Engineering. International Journal of Clothing Science and Technology 22(2/3): 187-201. 
8. Karthikeyan B, Sztandera LM (2010) Analysis of Tactile Perceptions of Textile Materials using Artificial Intelligence Techniques - Part -2: Reverse Engineering. International Journal of Clothing Science and Technology 22(2/3) 202-210.
9. Sztandera LM, Cardello AV, Winterhalter C, Schutz H (2013) Identification of the most significant comfort factors for textiles from processing mechanical, handfeel, fabric construction, and perceived tactile comfort data. Textile Research Journal 83(1): 34-43. 